\title{
Stereochemistry and Biogenesis of Serratinine ${ }^{1,2)}$
}

\author{
Yasuo Inubushi, Hisashi Ishit, Bompei Yasui, \\ and TAKashi Harayama \\ Faculty of Pharmaceutical Sciences, Osaka University ${ }^{3)}$
}

(Received March 31, 1967)

\begin{abstract}
The stereochemistry of serratinine containing its absolute configuration (E) has been established. The tentative biogenesis of serratinine from lycodoline type alkaloid has been also proposed.
\end{abstract}

In the preceding two papers ${ }^{4)}$ of this series, the structure establishment of serratinine(I) has been described. In this paper, we wish to present the full stereochemistry of serratinine including its absolute configuration and also refer to the tentative biogenesis of this alkaloid.

A/B Ring Junction and the Configuration of $\mathbf{C}_{13}-\mathbf{O H}-$ von Braun degradation of diacetylserratinine, ${ }^{*, 6)}$ (II) gave a neutral cyanobromide (III) in good yield which showed an

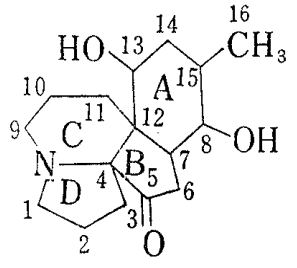

$I^{5)}$ $\mathrm{N}-$ cyano band at $2188 \mathrm{~cm}^{-1}$ in the IR spectrum. An attempt to hydrolyze two acetoxyl groups of the compound (III) with methanolic sodium hydroxide solution led to an unexpected result to give nearly quantitatively a ketal (IV), $\mathrm{C}_{17} \mathrm{H}_{24} \mathrm{O}_{3} \mathrm{~N}_{2}$. In the IR spectrum of the ketal (IV), a hydroxyl band at $3509 \mathrm{~cm}^{-1}$ and an $\mathrm{N}$-cyano band at $2188 \mathrm{~cm}^{-1}$ were observed but no carbonyl band did appear. Acetylation of the compound (IV) with acetic anhydride in pyridine gave acetyl ketal (V) whose IR spectrum showed an acetyl carbonyl band at $1721 \mathrm{~cm}^{-1}$ but no hydroxyl absorption. The NMR spectrum of this compound $(\mathrm{V})$ showed a $3 \mathrm{H}$ doublet $(J=6 \mathrm{cps})$ due to a secondary methyl group at $9.06 \tau$ and a $3 \mathrm{H}$ singlet attributable to an acetyl methyl at $7.97 \tau$ together with a multiplet due to a proton geminal to an acetoxyl group at $4.97 \tau$. In addition to these signals, the spectrum showed also the complex signals corresponding to three protons between $5.84 \tau$ and $6.18 \tau$ which could be assigned to protons attached to the carbon atoms bearing ether linkages. These observations can be well rationalized by assuming that treatment of cyanobromide (III) with alkali caused the ketal formation as shown in Chart 1. The only remaining problem to be elucidated is which of the two hydroxyl groups in serratinine participated in this ketal formation. This ambiguity was then clarified by inspection of NMR spectrum of dehydration product from the ketal (IV). Treatment of the ketal with phosphorus oxychloride in pyridine gave anhydro ketal (VI) whose NMR spectrum showed a $3 \mathrm{H}$ singlet due to a vinyl methyl group at $8.29 \tau$. This fact indicates that the free hydroxyl group of the ketal should

1) Studies on the Constituents of Domestic Lycopodium Genus Plants. Part VI. Part V: Chem. Pharm. Bull. (Tokyo), 16, 92 (1968).

2) The preliminary report of this work appeared in Tetrahedron Letters, 1966, 1551.

3) Location: 6-5, Toneyama, Toyonaka, Osaka-fu.

4) a) Part IV: Chem. Pharm. Bull. (Tokyo), 16, 82 (1968). b) Part V: ibid. 16, 92 (1968).

5) The numbering system of lycopodium alkaloids which is usually introduced, is based on the biogenesis of this type alkaloids suggested by Conroy. ${ }^{15}$ ) To that of serratinine, we adapted the analogous manner based on the tentative biogenesis proposed by us to serratinine.

6) Physical constants and preparation of the compound marked with an asterisk in this paper appeared in the preceding paper. ${ }^{4 a}$ ) 
be located on $\mathrm{C}_{8}$, in another words, that the $\mathrm{C}_{13}$-hydroxyl group participated in the ketal formation.

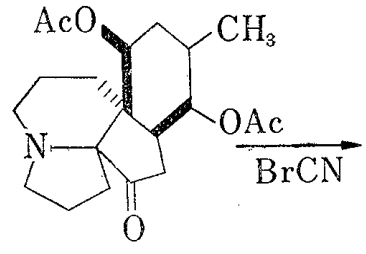

II

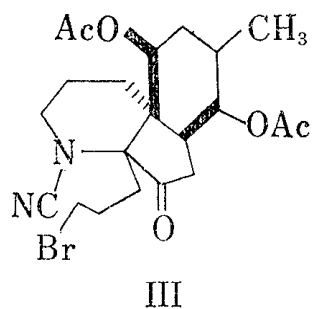

III

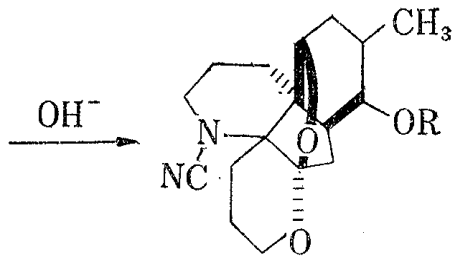

IV $: \mathrm{R}=\mathrm{H}$ $\mathrm{V}: \mathrm{R}=\mathrm{COCH}_{3}$

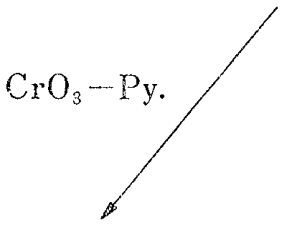

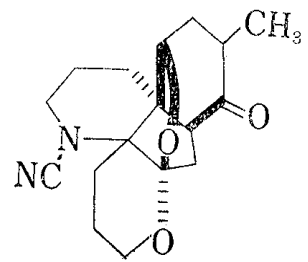

VII

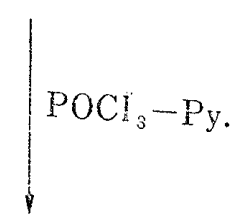

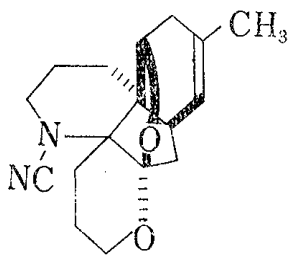

VI

Chart 1

In order to obtain the more confirmatory evidence, the following experiments were attempted. Oxidation of the ketal with chromium trioxide-pyridine complex ${ }^{7}$ furnished dehydroketal (VII) which showed a carbonyl band at $1692 \mathrm{~cm}^{-1}$ but no hydroxyl absorption in the IR spectrum. On the other hand, degradation of 13-acetyl-8-dehydroserratinine* (VIII) with cyanogen bromide, followed by alkali treatment gave the same dehydro ketal (VII) as ascertained by comparison of the IR spectra and the mixed melting point determination. Thus, the sequence of reactions unambiguously showed that the hydroxyl group on $\mathrm{C}_{13}$ had to participate in this ketal formation. The possibility of the alternative ring fission between nitrogen and $\mathrm{C}_{9}$, followed by the ketal formation has not been excluded but this ambiguity was settled by the Dreiding model inspections mentioned below. If the cyanogen bromide degradation caused the ring fission in the alternative direction, the ketal formation described above would not be happened because the Dreiding modle shows that the bromomethylene group in the supposed compound is sterically impossible to be connected with the carbonyl group. This observation together with the facile ketal formation led us to the conclusions that the structure of the ketal should be represented by the formula (IV) and that the $\mathrm{A} / \mathrm{B}$ ring juncture must be $c$ s, the $\mathrm{C}_{13}$ hydroxyl group, participating in the ketal formation, having to be $c$ is to the $\mathrm{C}_{12}-\mathrm{C}_{4}$ bond with respect to ring $\mathrm{A}$.

Configurations of $\mathbf{C}_{8}-\mathbf{O H}$ and $\mathbf{C}_{15}-\mathbf{C H}_{3}-$ Examination of the NMR spectrum of diacetyl benzylidene serratinine (IX) has unexpectedly provided the significant informations on the configurations of $\mathrm{C}_{15}-\mathrm{CH}_{3}$ group and $\mathrm{C}_{8}$-hydroxyl group. All derivatives of serratinine except anhydro derivatives have shown a $\mathrm{C}$-methy signal around $9.0 \tau$ and signals due to protons geminal to an acetoxyl group between $5.0 \tau$ and $5.4 \tau$ in their NMR spectra. In contrast with these data, the NMR spectrum of diacetyl benzylidene serratinine (IX) showed a $3 \mathrm{H}$ diffused doublet due to the methyl at $9.43 \tau$ and one $1 \mathrm{H}$ multiplet attributable to one of two protons

7) G.I. Poos, G.E. Arth, R.E. Reyler, and L.H. Sarett, J. Am. Chem. Soc., 75, 422 (1953). 
geminal to an acetoxyl group at 5.82 $\tau$. The high field shifts of these two signals in this compound can be probably explained by the shielding effect of a newly introduced benzene ring. On the basis of examination of models, the situation in which both methyl and proton concerned are subjuect simultaneously to the shielding effect, is only possible in a case that both $\mathrm{C}-\mathrm{CH}_{3}$ and $\mathrm{C}_{8}$ proton exist in trans diequatorial arrangement. Therefore, it may safely be said that the $\mathrm{C}_{8}$ hydroxyl group in serratinine (I) should be cis to the $\mathrm{C}-\mathrm{CH}_{3}$ group, namely this hydroxyl group being axial.

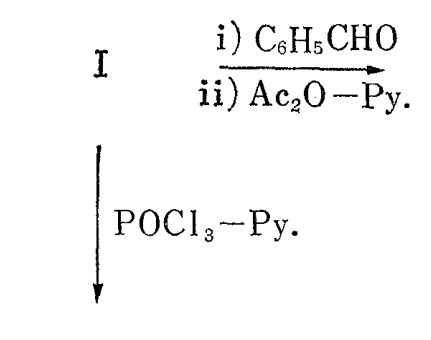

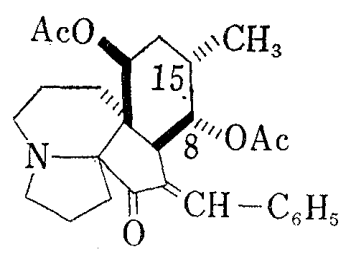

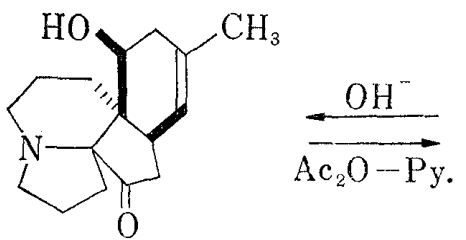

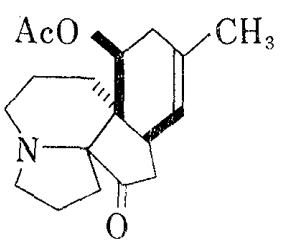

$\mathrm{X}$

$\mathrm{XI}$

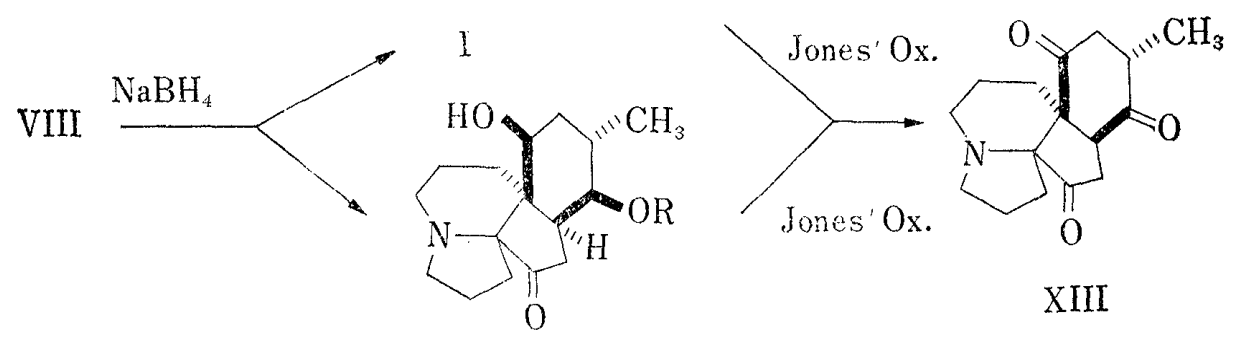<smiles>[R][R1]([H])=[W]</smiles><smiles>CO[C@H]1[C@@H](C)CC(=O)[C@@]23CCCN4CCCC2(CC4=O)[C@H]13</smiles>

$X V$<smiles>C1CCC2CCC2C1</smiles><smiles>CO[13C]#[13C]</smiles>

Chart 2

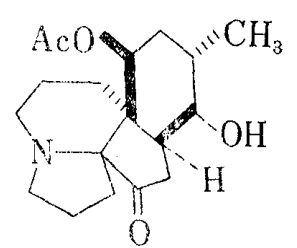

$\mathrm{XVI}$

Thisassignment to the $\mathrm{C}_{8}$ hydroxyl group was also supported by the following observations. Dehydration of serratinine (I) with phosphorus oxychloride in pyridine at room temperature gave a monoanhydride, ${ }^{* *, 8)}(\mathrm{X})$ which was verified as 8 -anhydroserratinine by the facts that

8) Physical constants and preparation of the compound marked with double asterisk in this paper appeared in the preceding paper. ${ }^{4 b}$ 
acetylation of the compound (X) furnished 13-acetyl-8-anhydroserratinine* (XI) described in the previous paper, and hydrolysis of 13-acetyl-8-anhydroserratinine regenerated the compound $(\mathrm{X})$. Consequently, the facile dehydration of the $\mathrm{C}_{8}$ hydroxyl group by such a mild condition suggests that this group would have axial orientation.

The second evidence was obtained from a comparsion of the properties between serratinine (I) and 8-episerratinine (XII). Reduction of 13-acetyl-8-dehydroserratinine* (VIII) with sodium borohydride in ethanol, followed by hydrolysis with alkali gave a mixture which showed virtually two spots on thin-layer chromatography. When the reduction product was chromatographed on alumina, the first eluate was found to be identical with serratinine and the successive elution with ethyl acetate then furnished another crystals (XII) whose IR spectrum showed hydroxyl bands at 3520 and $3340 \mathrm{~cm}^{-1}$ and a ketonic band at $1737 \mathrm{~cm}^{-1}$. Oxidation of the compound (XII) with Jones' reagent gave bisdehydroserratinine* (XIII) which was obtained from serratinine with the same reagent as mentioned in the previous paper. ${ }^{4 a}$ This result coupled with analytical data suggests that the latter compound (XII) would be 8-episerratinine.

The possibility of epimerization at $\mathrm{C}_{7}$ and/or $\mathrm{C}_{15}$ of the compound (VIII) during reduction process, would be ruled out since the curde reduction product, without being purified, showed virtually two spots corresponding to serratinine (I) and 8-episerratinine (XII), respectively, on thin-layer chromagtoraphy, and besides the total yield of both isomers was nearly quantitatively. Furthermore, inspections of models of the compounds which would be expected to be formed by the supposed epimerization, revealed that the epimerized compounds should have abnormally unfavorable structures with marked strain.

It has been well known that the epimer with the equatorial hydroxyl group is more strongly adsorbed on a chromatographic alumina column than the axial epimer, thus suggesting that the $\mathrm{C}_{8}$ hydroxyl group in serratinine would be axial, that in 8-episerratinine being equatorial. Now, a pair of epimers with regard to $C_{8}$ hydroxyl group came to our hands.

(A)

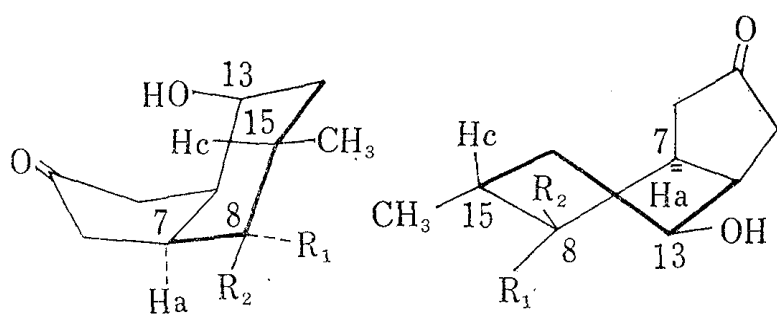

$\mathrm{I}: \mathrm{R}_{1}=\mathrm{OH}, \mathrm{R}_{2}=\mathrm{H}$

$\mathrm{XII}: \mathrm{R}_{1}=\mathrm{Hb}, \mathrm{R}_{2}=\mathrm{OH}$
(B)

$\mathrm{XIV}: \mathrm{R}_{1}=\mathrm{Hb}, \mathrm{R}_{2}=\mathrm{OAc}$

XVII $: \mathrm{R}_{1}=\mathrm{OAc}, \mathrm{R}_{2}=\mathrm{H}$
(C)

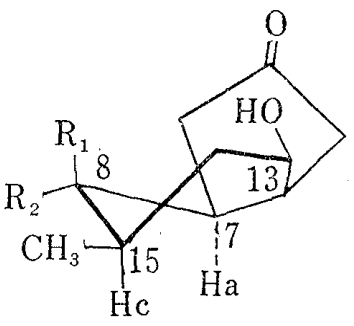

Chart 3

On the basis of the structure and stereochemical informations described so far, three conformational structures with regard to ring $\mathrm{A}$ are possible, i.e. one chair form (A) and two twist forms (B) and (C). Among these structures, in both (A) and (B) the secondary methyl group is cis to $\mathrm{C}_{7}-\mathrm{H}$ but in $(\mathrm{C})$ trans to $\mathrm{C}_{7}-\mathrm{H}$.

Finally, the geometry around $\mathrm{C}_{8}$ was revealed by means of application of NMR to the conformational problems. Acetylation of 8-episerratinine with acetic anhydride in pyridine gave a monoacetate (XIV) whose IR spectrum showed a hydroxyl band at $3270 \mathrm{~cm}^{-1}$ and carbonyl bands at 1747 and $1732 \mathrm{~cm}^{-1}$. The compound (XIV) was then oxidized with Jones' reagent to give a corresponding ketone $(\mathrm{XV})$ which was not identical with 13-acetyl-8dehydroserratinine* (VIII) obtained from 13-acetylserratinine* (XVI) under the same oxidation condition, thus indicating that acetylation of 8-episerratinine had occurred at the $\mathrm{C}_{8}$ hydroxyl group. The NMR spectrum of the monoacetate (XIV) showed a $1 \mathrm{H}$ clean quartet $\left(J_{1}=5.5 \mathrm{cps}\right.$ and $\left.J_{2}=11 \mathrm{cps}\right)$ due to a proton geminal to an acetoxyl group centered 
at $5.17 \tau$, while the singnals of the corresponding proton in 8-acetylserratinine* (XVII), an epimer of 8-acetyl-8-episerratinine, appeared as a $1 \mathrm{H}$ rather sharp multiplet (half band-width $5 \mathrm{cps}$ ) at $4.94 \tau$. This finding suggests that the $\mathrm{C}_{8}$ hydrogen of 8-acetyl-8-episerratinine (XIV) is axial and that of 8 -acetylserratinine* (XVII) is equatorial. The NMR spectrum of 8-acetyl-8-episerratinine was then utilized in conformational analysis around $\mathrm{C}_{8}$ acetoxyl group of this compound.

When the hydrogens at $\mathrm{C}_{7}, \mathrm{C}_{8}$ and $\mathrm{C}_{15}$ are designated as $\mathrm{H}_{2}, \mathrm{H}_{b}$ and $\mathrm{H}_{c}$, respectively, the magnitude of coupling constants between the coupled protons concerned were calculated.9) Dreiding model of conformation (A) reveals that the dihedral angle between $\mathrm{H}_{\mathrm{a}}$ and $\mathrm{H}_{\mathrm{b}}$ is approximately $45^{\circ}$, that between $\mathrm{H}_{b}$ and $\mathrm{H}_{\mathrm{c}}$ being nearly $170^{\circ}$. Thus, these values correspond to $4 \mathrm{cps}$ for $J_{\mathrm{a}-\mathrm{b}}$ and to $11 \mathrm{cps}$ for $J_{\mathrm{b}-\mathrm{c}}$, respectively. In conformation (B), the similar values would be expected. In the case of conformation $(C)$, however, $\mathrm{H}_{\mathrm{b}}$ is situated in parallel with both $\mathrm{H}_{\mathrm{a}}$ and $\mathrm{H}_{\mathrm{c}}$, so that each dihedral angle would be about $180^{\circ}$, suggesting that both coupling constants for $J_{\mathrm{a}-\mathrm{b}}$ and $J_{\mathrm{b}-\mathrm{c}}$ would be approximately $11 \mathrm{cps}$. Since the observed coupling constants were $5.5 \mathrm{cps}$ and $11 \mathrm{cps}$ which would be allocated to $J_{\mathrm{a}-\mathrm{b}}$ and $J_{\mathrm{b}-\mathrm{c}}$, respectively, 8-acetyl-8-episerratinine (XIV) could be depicted by a conformation (A) or (B), but not (C). Conclusively, we may deduce that both $\mathrm{C}_{8}$ hydroxyl group and a secondary methyl group are $c$ is to $\mathrm{C}_{7}-\mathrm{H}$.

Configuration of $\mathbf{C}_{4}-\mathbf{N}$ Bond-It has been shown that the large difference in basicity due to hydrogen bonding can be utilized in establishing stereochemistry of some alkaloids. The $\mathrm{p} K_{\mathrm{a}}$ values of some acetyl derivatives of serratinine are shown in Chart 4 .

That acetylation of $\mathrm{C}_{\mathbf{1 3}}$ hydroxyl group caused a fairly large decreasing in bsaicity could be accounted for in terms of the existence of specific interaction between $\mathrm{C}_{13}$ hydroxyl group and nitrogen.

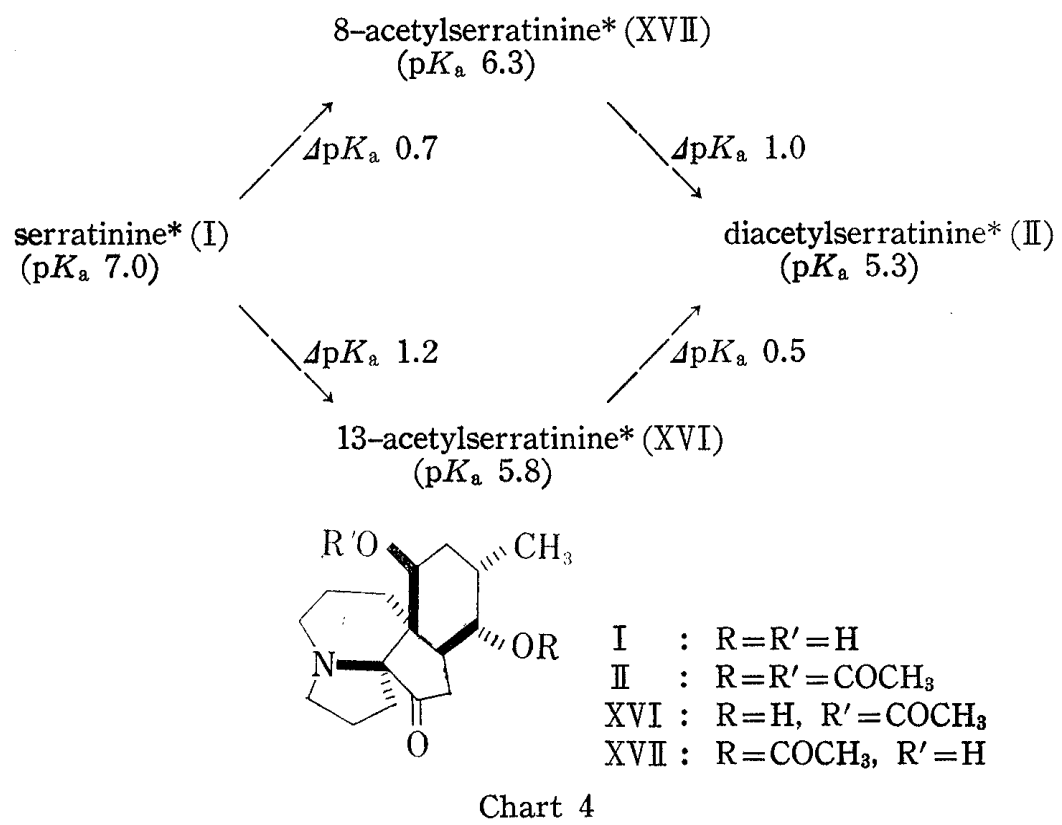

Inspections of medels reveal that only in the cis relationship of $\mathrm{C}_{4}-\mathrm{N}$ bond with respect to $\mathrm{C}_{12}-\mathrm{C}_{13}$ bond are both hydroxyl and nitrogen functions close enough together to give rise to an intramolecular hydrogen bonding. This deduction, however, is not definitely because the differences in basicity are not large enough to establish conclusively the stereochemistry of $\mathrm{C}_{4}-\mathrm{N}$ bond.

9) H. Conroy, "Advances in Organic Chemistry Methods and Results," Vol. II, 1960, Interscience Publishers, Inc., New York, p. 310. 
The correctness of this postulation was then shown firmly by the following chemical evidence.
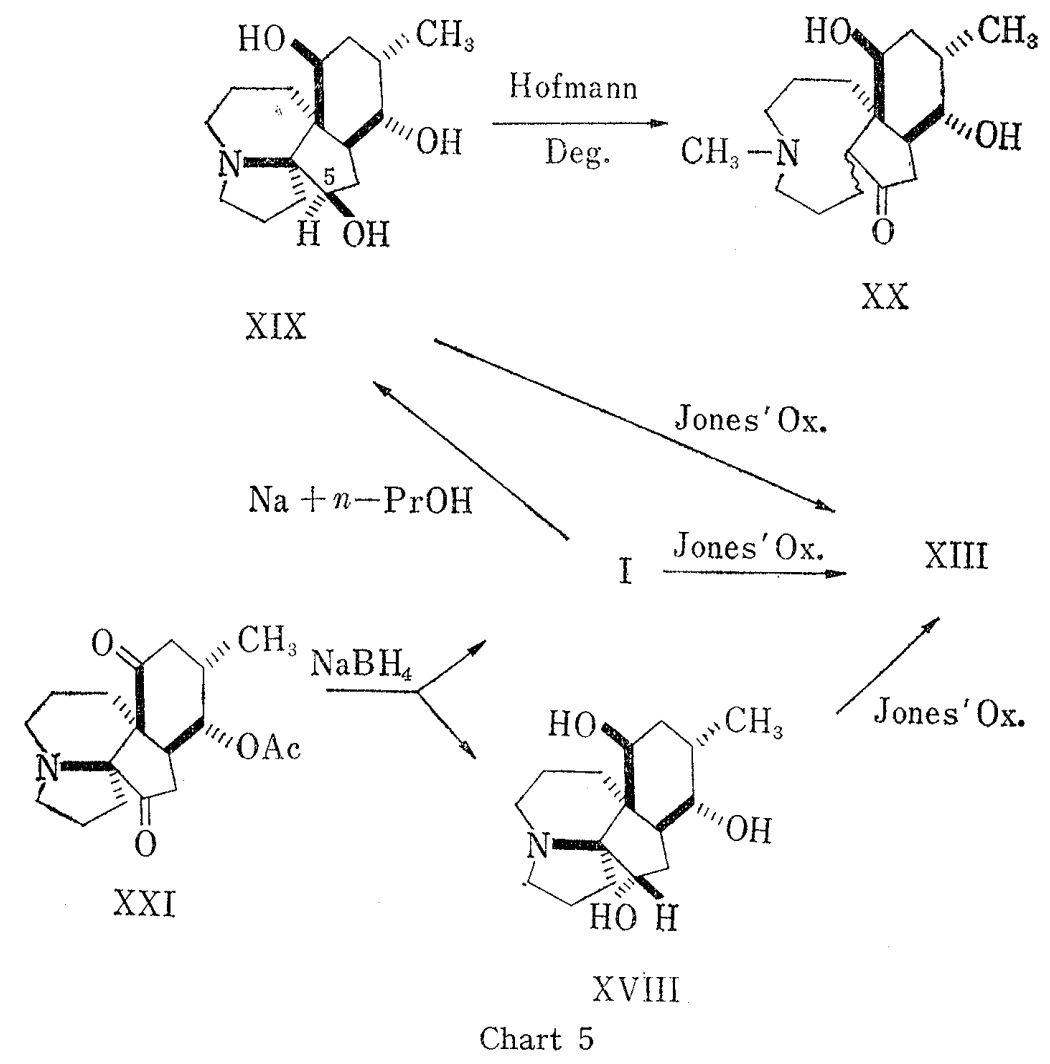

We have already described in a previous paper that lithium aluminum hydride reduction of serratinine (I) gave $\alpha$-dihydroserratinine $* *$ (XVIII). On the other hand, reduction of serratinine with sodium in $n$-propanol produced another dihydro compound, $\beta$-dihydroserratinine (XIX) which was confirmed to be an epimer of $\alpha$-dihydroserratinine with regard to $\mathrm{C}_{5}$ hydroxyl group by the fact that both dihydro compounds were oxidized with Jones' reagent to give bisdehydroserratinine* (XIII). On heating at $160^{\circ}$ under reduced pressure, $\beta$-dihydroserratinine (XIX) methohydroxide was subjected to Hofmann degradation to afford a basic methine (XX), $\mathrm{C}_{17} \mathrm{H}_{29} \mathrm{O}_{3} \mathrm{~N}$, in excellent yield. The IR spectrum of this methine showed a hydroxyl band at $3401 \mathrm{~cm}^{-1}$ and a ketonic band at $1709 \mathrm{~cm}^{-110)}$ and the NMR spectrum showed a $3 \mathrm{H}$ singlet due to an $\mathrm{N}$-methyl group at $7.73 \tau$ and no signal due to an olefinic proton. Meanwhile, under the same condition, $\alpha$-dihydroserratinine (XVIII) methohydroxide afforded an unseparable mixture which showed many spots on thin-layer chromatography. These facts indicate that

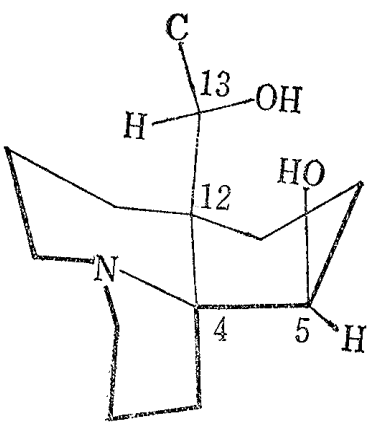

(D) the $\mathrm{C}_{5}$ hydrogen of $\beta$-dihydroserratinine should be trans to $\mathrm{C}_{4}-\mathrm{N}$ bond as shown in formula (D).

At this point, the configuration of $\mathrm{C}_{5}$ hydrogen of $\beta$-dihydroserratinine must be settled. Reduction of 8-acetyl-13-dehydroserratinine* (XXI) with sodium borohydride gave a mixture which showed virtually two spots on thin-layer chromatography. Chromatography on

10) The band of this carbonyl group gave rather lower frequencies than those expected for five membered ketones but we now have some evidences that this anomalous position could be ascribed to hydrogen bonding. These findings will be reported in other paper. 
alumina resulted in separation of two compounds, i.e. serratinine and $\alpha$-dihydroserratinine** (XVIII) which were identifies with authentic specimens, respectively. In contrast with this result, the compounds leaving the $C_{13}$ hydroxyl group intact, like serratinine or 13-

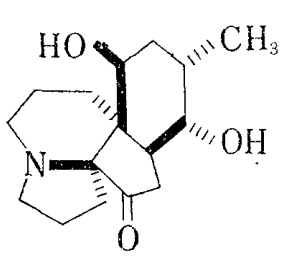

(E) acetyl-8-dehydroserratinine* (VIII), resisted to reduction of $\mathrm{C}_{5}$ ketone function with the same reagent even under the forced condition. The insusceptibility to the reagent in the latter cases may be ascribed to the steric hindrance to approach of the metal hydride ion to either side of the $\mathrm{C}_{5}$ carbonyl function, and this steric interference should be partly due to the $\mathrm{C}_{13}$ hydroxyl group. Therefore, in 8-acetyl-13dehydroserratinine (XXI) which possesses a carbonyl group instead of a hydroxyl group at $\mathrm{C}_{13}$ position, the metal hydride ion can only approach from the less hindered side, i.e. the side on which the $\mathrm{C}_{\mathbf{1 3}}$ hydroxyl group was originally held. In this case, the hydride ion could approach competitively to either the $\mathrm{C}_{5}$ ketone group or the $\mathrm{C}_{\mathbf{1 3}}$ ketone group. If the hydride ion approaches first to the $\mathrm{C}_{5}$ ketone group, the initial reduction product could be then subject to further reduction to give $\alpha-$ dihydroserratinine and if the hydride ion approaches to the $\mathrm{C}_{13}$ ketone first, the hydroxyl group newly introduced, rejects further approach of the reagent to the $\mathrm{C}_{5}$ ketone group, so that the reaction does not proceed any more and serratinine is the only reduction product. Consequently, these considerations allow us to deduce that the configuration of $\mathrm{C}_{5}$ hydrogen in $\alpha$-dihydroserratinine (XVIII) should be the same configuration as that of $\mathrm{C}_{13}$ hydroxyl group of serratinine. In other words, the $\mathrm{C}_{5}$ hydrogen in $\beta$-dihydroserratinine (XIX) is trans to the $\mathrm{C}_{13}$ hydroxyl group. Since it has been shown by Hofmann degradation studies on two epimeric dihydroserratinines that the $\mathrm{C}_{5}$ hydrogen in $\beta$-dihydroserratinine (XIX) would be trans to the $\mathrm{C}_{4}-\mathrm{N}$ bond, the configuration of the $\mathrm{C}_{4}-\mathrm{N}$ bond in serratinine must be cis to the $\mathrm{C}_{13}$ hydroxyl group. Consequently, serratinine should be represented by the stereostructure $(\mathrm{E})$ or its mirror image.

Absolute Configuration-The final probelm to be discussed on the stereochemistry of serratinine is concerned with the absolute configuration of this alkaloid. Wolff-Kishner reduction ${ }^{11)}$ of 8-acetyl-13-dehydroserratinine (XXI) afforded an alcohol, 5-deoxo-13-deoxyserratinine (XXII), which was then oxidized with chromium trioxide in $90 \%$ acetic acid to give a ketone, 8-dehydro-5-deoxo-13-deoxyserratinine (XXIII). The optical rotatory dispersion curve of this ketone gave a positive Cotton effect with extreme at 273 and $308 \mathrm{~m} \mu$; $\mathrm{a}=$ 47.58. The positive sign of this curve is in accord with the predicted sign from the octant diagram (F) for the formula (XXIII). Consequently, serratinine should be represented by the formula $(\mathrm{E})$ and not its mirror image.

This conclusion was also supported by the result obtained from application of the benzoate rule.

Treatment of 8-episerratinine (XII) with benzoyl chloride in pyridine gave 8-benzoyl8-episerratinine (XXIV). Application of the benzoate rule, ${ }^{12,13}$ ) to a pair of 8-episerratinine

11) D.H.R. Barton, D.A.J. Ives, and B.R. Thomas, J. Chem. Soc., 1955, 2056.

12) J.H. Brewster, Tetrahedron, 13, 106 (1961).

13) In a preliminary communication, ${ }^{2}$ we have applied the benzoate rule to a pair of 13-acetylserratinine and its benzoate. However, the derivations of their $[M]_{\mathrm{D}}$ values by changes of solvents employed were fairly large. For instance, 13-acetyl-8-benzoylserratinine showed $[M]_{\mathrm{D}}:+62.3^{\circ}$ in ethanol solution, but $[M]_{\mathrm{D}}-23.9^{\circ}$ in chloroform solution. Since the scattering $[M]_{\mathrm{D}}$ values can be probably ascribed to the deviation of ring A by the solvation, application of the benzoate rule to such compounds would not be suitable, 8-Benzoyl-8-episerratinine seems to be more rigid compound than 13-acetyl8-benzoylserratinine because the former has a more favorable equatorial benzoyloxy group at $\mathrm{C}_{8}$. Since deviation of conformation of the compound could be perceived by measuring NMR spectrum and its conformation has been presumed by examining the signal due to a proton geminal to a benzoyloxy group in its NMR spectrum taken in chloroform solution, it is desirable that the optical rotation shenld be measured in the same solvent as that employed in NMR measurement. 


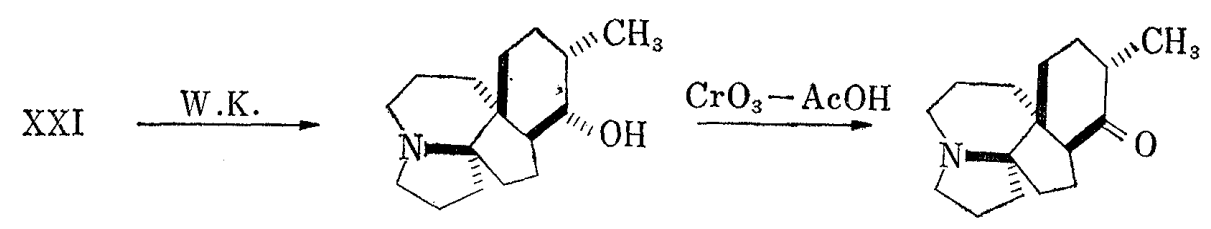

XXII

XXIII
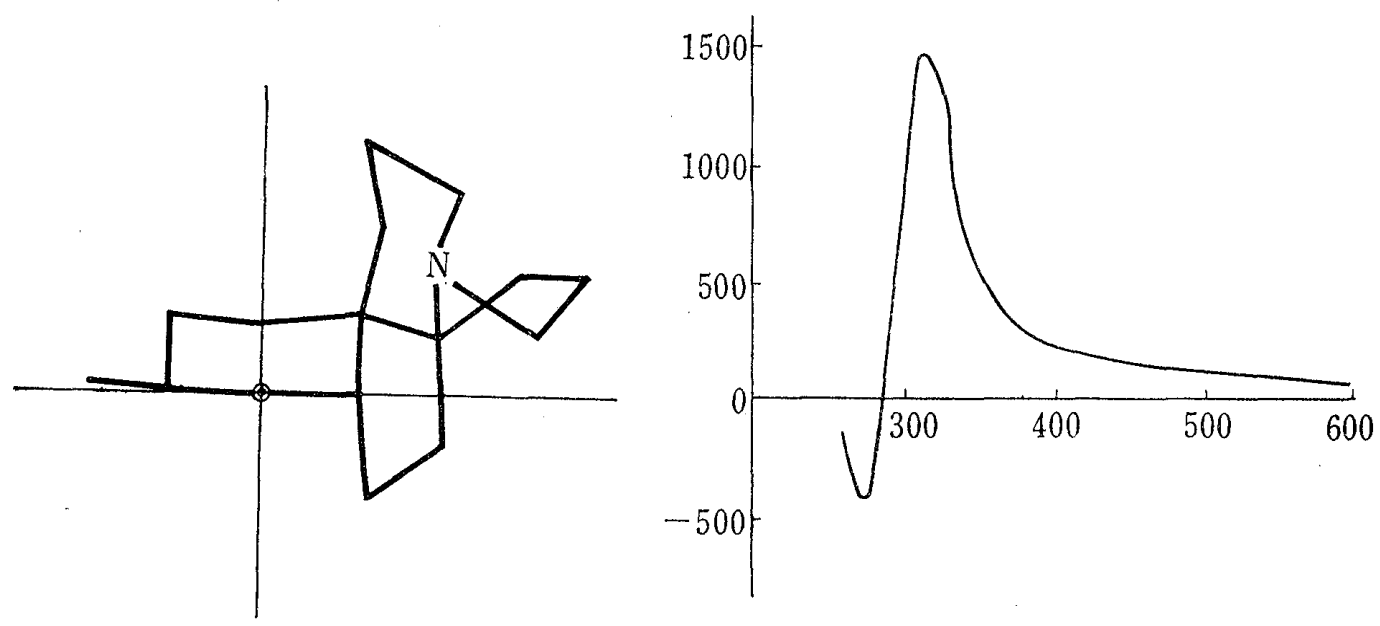

(F)

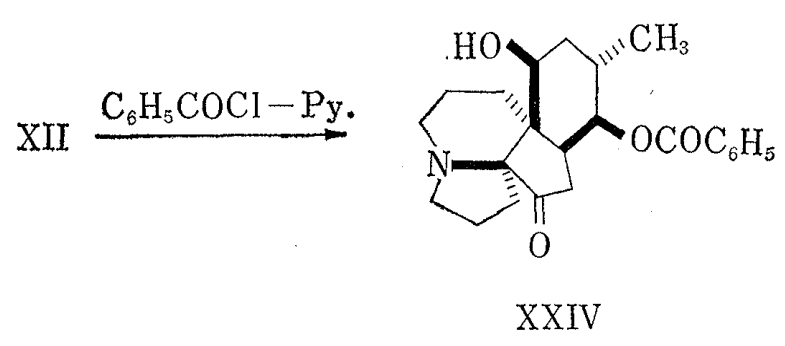

Chart 6

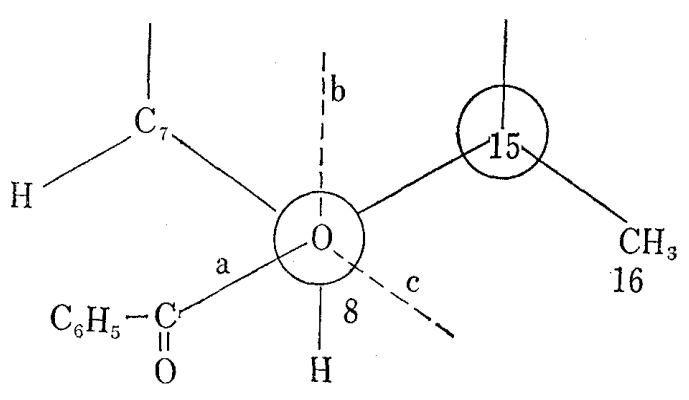

(G)

(XII) and its benzoate was attempted: $[M]_{\mathrm{D}}$ (benzoate) $+212.06^{\circ}-[M]_{\mathrm{D}}(\mathrm{ol})+77.66^{\circ}=\Delta$ $[M]_{\mathrm{D}}+134.40^{\circ}$ (in chloroform). Several years ago, Brewster clearly has explained the benzoate rule by his dissymmetry rule. ${ }^{14)}$ When we adapt his interpretation, our experimentally observed result can be rationalized as follows. Newman's projection of the surroundings of the bond between $\mathrm{O}$ and $\mathrm{C}_{8}$ in 8-benzoyl-8-episerratinine (XXIV) shows three possible conformers with regard to $\mathrm{O}-\mathrm{CO}$ bond as shown in Chart 6 . However, two of them, (b) and (c), can be excluded for the reason that both of them have 1,3-diaxial-like interaction and seem to be unfavorable forms. The $\mathrm{O}-\mathrm{CO}$ bond in the most preferable conformer (a) is located between $\mathrm{C}_{8}-\mathrm{C}_{7}$ and $\mathrm{C}_{8}-\mathrm{H}$ bonds.

Since the observed $\Delta[M]_{\mathrm{D}}$ showed positive sign which is expected to the Newman's projection (G) for 8-benzoyl-8-episerratinine (XXIV), it could be concluded that the absolute configuration of the asymmetric center at $\mathrm{C}_{8}$ in 8 -episerratinine (XII) is $\mathrm{R}$-form and that in serratinine (I), accordingly, being $\mathrm{S}-$ form. These conclusions are consistent with the former result obtained from the positive Cotton effect for 8-dehydro-13-deoxyserratinine.

Biogenesis_- It has been suggested by Conroy ${ }^{15)}$ that the skeleton inherent in lycopodium alkaloids might owe to the condensation of two eight carbon polyacetate straight chains.

14) J.H. Brewster, J. Am. Chem. Soc., 81, 5475, 5483, 5493 (1959).

15) H. Conroy, Tetrahedron Letters, 1960, 34. 


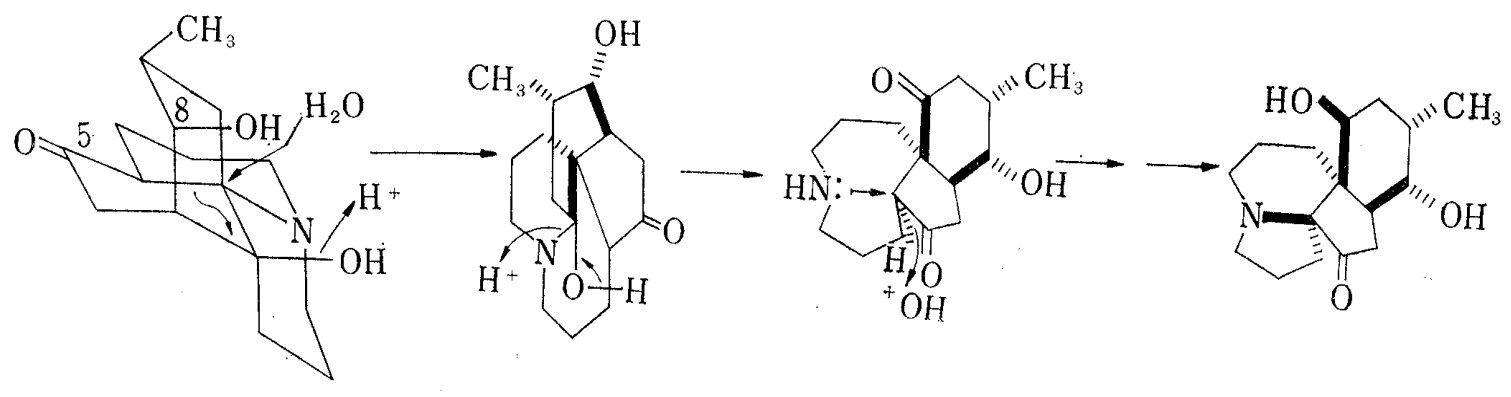

Lycodoline type alkaloid

Chart 7

However, serratinine is a new representative to which the biogenesis sugested so far could not directly be applied. We, now, wish to propose the extended biogenetic schemes to that of serratinine on the basis of Conroy's biogenesis. If lycodoline or a close related derivative is the precursor of serratinine, this alkaloid is plausibly formed through the postulated steps from the supposed precursor as shown in Chart 7, although the sequence is obscure. This postulation seems to be reasonable, since lycodoline was isolated from the same plant together with serratinine and the presented absolute configuration of serratinine concures with that of an alkaloid which might be expected to arise from the lycodoline type alkaloid through the postulated transformations. The additional $\mathrm{C}_{8}$ hydroxyl group in serratinine seems to be quite reasonable, since the oxygen functions, lycopodium alkaloids are most commonly found at $\mathrm{C}_{5}, \mathrm{C}_{8}$ and $\mathrm{C}_{13}$, especially lycofawcine ${ }^{\mathbf{1 6})}$ possessing three oxygen functions at these positions. Although these biogenetic schemes are plausible enough and the experimental support is required, this proposed biogenetic pathway would be still useful for predicting the structures of this series of alkaloids which seem to be isolated from the plant.

\section{Experimental $\left.{ }^{17}\right)$}

Diacetylserratinine Cyanobromide (III) _ - A mixture of $1 \mathrm{~g}$ of diacetylserratinine* (II) and $10 \mathrm{~g}$ of cyanogen bromide in $40 \mathrm{ml}$ of dry $\mathrm{CHCl}_{3}$ was allowed to stand at room temperature for $40 \mathrm{hr}$. The residue was taken up in $\mathrm{CHCl}_{3}$ and washed with aq. $5 \% \mathrm{HCl}$ solution. Some quantity of starting material (II) was recovered from the acidic washings. The chloroform solution was dried over anhydr. $\mathrm{K}_{2} \mathrm{CO}_{3}$ and removal of the solvent gave $0.91 \mathrm{~g}$ of crystals which were recrystallized from acetone-ether to afford leaflets (III) mp 200-202,$[a]_{\mathrm{D}}^{23}-23.1^{\circ}(c=1.02, \mathrm{EtOH})$. Anal. Calcd. for $\mathrm{C}_{21} \mathrm{H}_{29} \mathrm{O}_{5} \mathrm{~N}_{2} \mathrm{Br}: \mathrm{C}, 53.73 ; \mathrm{H}, 6.23$. Found: $\mathrm{C}, 53.73 ; \mathrm{H}, 6.24$. IR cm ${ }^{-1}: v_{\mathrm{C} \equiv \mathrm{N}} 2188 ; v_{\mathrm{C}=0} 1739,1727 ; v_{\mathrm{C}-0} 1230$. NMR $\tau: 4.93(1 \mathrm{H}, \mathrm{m} .,>\mathrm{CH}-\mathrm{OAc})$; $5.36(1 \mathrm{H}, \mathrm{m} .,>\mathrm{CH}-\mathrm{OAc}) ; 7.97\left(3 \mathrm{H}, \mathrm{s.},-\mathrm{OCOCH}_{3}\right) ; 8.08\left(3 \mathrm{H}, \mathrm{s} .,-\mathrm{OCOCH}{ }_{3}\right) ; 9.12\left(3 \mathrm{H}, \mathrm{d} ., J=6 \mathrm{cps},>\mathrm{CH}-\mathrm{CH}_{3}\right)$.

Ketal (IV)—A solution of $150 \mathrm{mg}$ of diacetylserratinine cyanobromide (III) in $15 \mathrm{ml}$ of $\mathrm{MeOH}$ containing $400 \mathrm{mg}$ of $\mathrm{KOH}$ was refluxed for 30 minutes, cooled and neutralized with aq. $5 \% \mathrm{AcOH}$ solution. The solution was concentrated in vacuo, diluted with water and extracted with $\mathrm{CHCl}_{3}$. The chloroform extract was dried over anhydr. $\mathrm{K}_{2} \mathrm{CO}_{3}$ and removal of the solvent gave $63 \mathrm{mg}$ of crystals which were recrystallized from acetone to give colorless needles, mp $239-240^{\circ},[\alpha]_{D}^{23}-27.5^{\circ}(c=1.01, \mathrm{EtOH})$. Anal. Calcd. for $\mathrm{C}_{17} \mathrm{H}_{24} \mathrm{O}_{3} \mathrm{~N}_{2}: \mathrm{C}, 67.08 ; \mathrm{H}, 7.95$. Found: C, 66.94; H, 8.02. IR cm-1: $v_{0-\mathrm{H}} 3509 ; v_{\mathrm{C} \equiv \mathrm{N}}$ 2188.

Acetylketal (V) - A mixture of $100 \mathrm{mg}$ of ketal (IV) and $3 \mathrm{ml}$ of acetic anhydride in $3 \mathrm{ml}$ of pyridine was heated at $100^{\circ}$ for $3 \mathrm{hr}$, cooled and evaporated to dryness in vacuo. The residue was taken up in water and extracted with $\mathrm{CHCl}_{3}$. The extract was dried over anhydr. $\mathrm{K}_{2} \mathrm{CO}_{3}$ and the solvent was evaporated. The residue in benzene was chromatographed on alumina. Elution with benzene afforded $70 \mathrm{mg}$ of solid mass which was recrystallized from ether to give colorless leaflets $(\mathrm{V}), \mathrm{mp} 184.5-185.5^{\circ},[\alpha]_{\mathrm{D}}^{23}-19.6^{\circ}$ $(c=0.79, \mathrm{EtOH})$. Anal. Calcd. for $\mathrm{C}_{19} \mathrm{H}_{26} \mathrm{O}_{4} \mathrm{~N}_{2}: \mathrm{C}, 65.87 ; \mathrm{H}, 7.57$. Found: $\mathrm{C}, 65.62 ; \mathrm{H} 7.67$. IR $\mathrm{cm}^{-1}$ : $v_{\mathrm{C} \equiv \mathrm{N}} 2193 ; v_{\mathrm{C}=0} 1721 ; v_{\mathrm{C}-\mathrm{O}} 1245 . \quad \mathrm{NMR} \tau: 4.97(1 \mathrm{H}, \mathrm{m} .,>\mathrm{CH}-\mathrm{OAc}) ; 5.84-6.18\left(3 \mathrm{H}, \mathrm{m} .,>\mathrm{CH}-\mathrm{O}-\mathrm{C}_{1}-\mathrm{O}-\mathrm{C} \underline{H}_{2}-\right)$; 7.97 (3H, s., $\left.-\mathrm{OCOC} \underline{H}_{3}\right) ; 9.06\left(3 \mathrm{H}\right.$, d., $\left.J=6 \mathrm{cps},>\mathrm{CH}-\mathrm{CH}_{3}\right)$.

16) W.A. Ayer, W.R. Bowman, P. Kebarle, and R.H. Burnell, Can. J. Chem., 43, 328 (1965).

17) Refer to the footnote 19) in the preceding paper (Part IV). 
Anhydroketal (VI) — To a solution of $50 \mathrm{mg}$ of ketal (IV) in $1 \mathrm{ml}$ of dry pyridine was added 2 drops of $\mathrm{POCl}_{3}$. The mixture was allowed to stand at room temperature overnight, poured into water, made acidic with conc. $\mathrm{HCl}$ and extracted with $\mathrm{CHCl}_{3}$. The extract was dried over anhydr. $\mathrm{K}_{2} \mathrm{CO}_{3}$ and the solvent was evaporated. The residue in benzene was chromatographed on alumina. Elution with benzene gave $15 \mathrm{mg}$ of solid mass which was recrystallized from benzene-ether to furnish colorless prisms (VI), $\mathrm{mp}$ 175178 . Anal. Calcd. for $\mathrm{C}_{17} \mathrm{H}_{22} \mathrm{O}_{2} \mathrm{~N}_{2}: \mathrm{C}, 71.30 ; \mathrm{H}, 7.74$. Found: $\mathrm{C}, 71.38 ; \mathrm{H}, 7.92$. IR cm ${ }^{-1}: v_{\mathrm{C} \equiv \mathrm{N}} 2183$. MNR

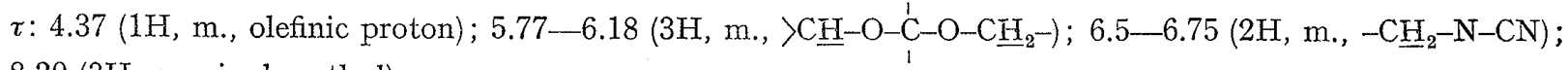
$8.29(3 \mathrm{H}, \mathrm{s}$, vinyl methyl).

Dehydroketal (VII) — A solution of $100 \mathrm{mg}$ of ketal (IV) in $1 \mathrm{ml}$ of pyridine was added to a stirred solution of $1 \mathrm{ml}$ of pyridine containing $100 \mathrm{mg}$ of chromium trioxide. The mixture was stirred at room temperature for $20 \mathrm{hr}$, poured into ice-water, made alkaline with $\mathrm{NH}_{4} \mathrm{OH}$, and extracted with $\mathrm{CHCl}_{3}$. The extract was dried over anhydr. $\mathrm{K}_{2} \mathrm{CO}_{3}$ and evaporated to dryness in vacuo. The residue in $\mathrm{CHCl}_{3}$ was chromatographed on alumina. Elution with $\mathrm{CHCl}_{3}$ gave $58 \mathrm{mg}$ of crystals which were recrystallized from acetone to afford colorless prisms (VII), mp 284-285. Anal. Calcd. for $\mathrm{C}_{17} \mathrm{H}_{22} \mathrm{O}_{3} \mathrm{~N}_{2}: \mathrm{C}, 67.52 ; \mathrm{H}, 7.33$; $\mathrm{N}$, 9.27. Found: C, 67.79; H, 7.62; N, 9.13. IR $\mathrm{cm}^{-1}: v_{\mathrm{C} \equiv \mathrm{N}} 2183 ; v_{\mathrm{C}=0} 1692$. NMR $\tau: 5.7-6.2$ (3H, m., $>$ CH-O-C-O-O-CH ${ }_{2}^{-}$); 8.96 (3H, d., $\left.J=6 \mathrm{cps},>\mathrm{CH}-\mathrm{CH}_{3}\right)$.

Formation of Dehydroketal (VII) from 13-Acetyl-8-dehydroserratinine*(VIII) — A mixture of $150 \mathrm{mg}$ of 13-acetyl-8-dehydroserratinine* (dehydromonoacetylserratinine $\mathrm{Ir}$ (VIII)) in dry $\mathrm{CHCl}_{3}$ containing $1.5 \mathrm{~g}$ of cyanogen bromide was allowed to stand at room temperature for $40 \mathrm{hr}$. The chloroform and excess cyanogen bromide were removed under reduced pressure. The residue was taken up in $\mathrm{CHCl}_{3}$, washed with aq. $5 \% \mathrm{HCl}$ solution and dried over anhydr. $\mathrm{K}_{2} \mathrm{CO}_{3}$. Removal of the solvent afforded $90 \mathrm{mg}$ of crystals which were recrystallized from acetone-ether to give colorless plates, mp 169-172 ${ }^{\circ}$ Anal. Calcd. for $\mathrm{C}_{19} \mathrm{H}_{25} \mathrm{O}_{4} \mathrm{~N}_{2} \mathrm{Br}: \mathrm{C}, 53.65 ; \mathrm{H}, 5.93$. Found: $\mathrm{C}, 53.61 ; \mathrm{H}, 5.93$. IR $\mathrm{cm}^{-1}: \nu_{\mathrm{C} \equiv \mathrm{N}} 2193 ; \nu_{\mathrm{C}=0} 1745,1733,1698$; $v_{\mathrm{C}-\mathrm{O}} 1233$.

A solution of $100 \mathrm{mg}$ of 13-acetyl-8-dehydroserratinine cyanobormide in $12 \mathrm{ml}$ of $\mathrm{MeOH}$ containing $0.3 \mathrm{~g}$ of $\mathrm{KOH}$ was heated for 30 minutes under reflux, cooled and neutralized with aq. $5 \%$ AcOH solution. The solution was then concentrated in vacuo, diluted with water and extracted with $\mathrm{CHCl}_{3}$. The extract was dried over anhydr. $\mathrm{K}_{2} \mathrm{CO}_{3}$. Removal of the solvent and recystallization of the residue from acetone gave $21 \mathrm{mg}$ of colorless prisms, (VII), $\mathrm{mp} 283-285^{\circ}$, which were identified with the sample derived from the ketal (IV) by comparison of IR spectra and mixed melting point determination.

Diacetylbenzylidene Serratinine (IX) — A solution of $1 \mathrm{~g}$ of benzylidene serratinine* in $15 \mathrm{ml}$ of pyridine containing $15 \mathrm{ml}$ of acetic anhydride was heated at $100^{\circ}$ for $4.5 \mathrm{hr}$, cooled and evaporated to dryness in vacuo. The residue was dissolved in water, made alkaline with $\mathrm{NH}_{4} \mathrm{OH}$ and extracted with $\mathrm{CHCl}_{3}$. The extract was dried over anhydr. $\mathrm{K}_{2} \mathrm{CO}_{3}$ and the solvent was evaporated. The residue in benzene was chromatographed on alumina. Elution with benzene followed by ether gave $786 \mathrm{mg}$ of crystals which were recrystallized from $n$-hexane to afford pale yellow plates, (IX), mp 184-185 . Anal. Calcd. for $\mathrm{C}_{22} \mathrm{H}_{38} \mathrm{O}_{5} \mathrm{~N}$ : $\mathrm{C}, 71.81 ; \mathrm{H}, 7.37$. Found: C, 71.90; H, 7.39. IR cm ${ }^{-1}: v_{\mathrm{C}=0} 1727 ; v_{\mathrm{C}=\mathrm{C}} 1625, v_{\text {aromatic }} 1600,1572 ; v_{\mathrm{C}-0}$ 1239, 1224. UV $\lambda_{\max } \mathrm{m} \mu(\log \varepsilon): 228$ (3.88), $291.5(4.26) ; \nu_{\max }^{\mathrm{E} \text { toH-HCl }} \mathrm{m} \mu(\log \varepsilon): 236(3.71), 309$ (4.25). NMR $\tau: 2.3-2.8(5 \mathrm{H}, \mathrm{m}$. , aromatic protons); $4.56(1 \mathrm{H}, \mathrm{m}$., olefinic protons); $5.31(1 \mathrm{H}, \mathrm{m} .,>\mathrm{CH}-\mathrm{OAc}) ; 5.82(1 \mathrm{H}$, m., $>\mathrm{CH}-\mathrm{OAc}$ ); 7.95 ( $\left.3 \mathrm{H}, \mathrm{s.},-\mathrm{OCOC \textrm {H } _ { 3 }}\right) ; 8.07$ ( $3 \mathrm{H}$, s., $-\mathrm{OCOC \textrm {H } _ { 3 }}$ ); $9.43\left(3 \mathrm{H}\right.$, diffused d., $\left.J=6 \mathrm{cps},>\mathrm{CH}-\mathrm{CH}_{3}\right)$.

8-Anhydroserratinine (X) - To a solution of $150 \mathrm{mg}$ of serratinine (I) in $3 \mathrm{ml}$ of pyridine was added $0.5 \mathrm{ml}$ of $\mathrm{POCl}_{3}$ and the mixture was then allowed to stand at room temperature overnight and evaporated to dryness in vacuo. The residue was dissolved in aq. $5 \% \mathrm{HCl}$ solution, washed with ether, made alkaline with $\mathrm{NH}_{4} \mathrm{OH}$ and extracted with $\mathrm{CHCl}_{3}$. The extract was dried over anhydr. $\mathrm{K}_{2} \mathrm{CO}_{3}$ and the solvent was evaporated. The residue in benzene was chromatographed on alumina. Elution with benzene followed by ether gave $55 \mathrm{mg}$ of solid mass which was recrystallized from benzene to afford colorless needles (X), mp $196-198^{\circ}$. This substance was identical with anhydroserratinine II* $(\mathrm{X})$, independently obtained by dehydration of monoacetylserratinine II* (i.e. 13-acetyl-8-hydroxy derivative of serratinine) (XI), followed. by hydrolysis, as evidenced by mixed melting point determination and infrared spectra comparison. Acetylation of $50 \mathrm{mg}$ of 8-anhydroserratinine (X) by the same manner as described in acetylation of the ketal (IV), gave $25 \mathrm{mg}$ of 13-acetyl-8-anhydroserratinine* (XI).

Reduction of 13-Acetyl-8-dehydroserratinine* (VIII) with $\mathrm{NaBH}_{4}$ (8-episerratinine (XII)) —-To a solution of $108 \mathrm{mg}$ of 13-acetyl-8-dehydroserratinine* (VIII) in $200 \mathrm{ml}$ of EtOH was gradually added $400 \mathrm{mg}$ of $\mathrm{NaBH}_{4}$ in small portions under reflux during $4 \mathrm{hr}$. A solution of $100 \mathrm{mg}$ of $\mathrm{NaOH}$ in $10 \mathrm{ml}$ of water was then added to the reaction mixture and the mixture was heated for further 15 minutes. After decomposition of the excess reagent with $\mathrm{AcOH}$, the reaction mixture was diluted with water, made alkaline with $\mathrm{NH}_{4} \mathrm{OH}$ and extracted with $\mathrm{CHCl}_{3}$. The chloroform extract was dried over anhydr. $\mathrm{K}_{2} \mathrm{CO}_{3}$ and the solvent was evaporated. The residue which upon thin-layer chromatography showed virtually two spots, was dissolved in $\mathrm{CHCl}_{3}$ and the chloroform solution was chromatographed on alumina. Elution with $\mathrm{CHCl}_{3}$ gave $25 \mathrm{mg}$ of colorless pillars, $\mathrm{mp} 244-245^{\circ}$, whose IR spectrum was identical with that of serratinine (I). Further elution with ethyl acetate afforded $63.6 \mathrm{mg}$ of crystalline mass which was recrystallized from ethyl acetate 
to give colorless needles, 8-episerratinine (XII), mp 234-237,$[\alpha]_{\mathrm{D}}^{14}+27.8^{\circ}\left(c=1.0, \mathrm{CHCl}_{3}\right) ;[\alpha]_{\mathrm{D}}^{32}+22.43^{\circ}$ $\left(c=1.11\right.$, EtOH). Anal. Calcd. for $\mathrm{C}_{\mathbf{1 6}} \mathrm{H}_{25} \mathrm{O}_{3} \mathrm{~N}: \mathrm{C}, 68.78 ; \mathrm{H}, 9.02$. Found: C, 68.77; H, 8.95. IR $\mathrm{cm}^{-1}$ : $v_{0-\mathrm{H}} 3520,3340 ; v_{\mathrm{C}=0} 1737$.

Oxidation of 8-Episerratinine (XII) to Bisdehydroserratinine* (XIII)_-To a stirred solution of $45 \mathrm{mg}$ of 8-episerratinine (XII) in $5 \mathrm{ml}$ of acetone was added $1 \mathrm{ml}$ of Jones' reagent under cooling. The mixture was stirred at $40^{\circ}$ for $1 \mathrm{hr}$. After decomposition of the excess reagent with $\mathrm{MeOH}$, the solution was concentrated to a half volume, diluted with water and extracted with ether. The extract was dried over anhydr. $\mathrm{K}_{2} \mathrm{CO}_{3}$ and the solvent was evaporated. Distillation of the residue at $160^{\circ}(2 \mathrm{~mm} \mathrm{Hg})$ and recrystallization of the distillate from ether gave $23 \mathrm{mg}$ of colorless prisms, $\mathrm{mp} 158-160^{\circ}$, whose IR spectrum was identical with that of bisdehydroserratinine* (XIII).

Monoacetyl-8-episerratinine (XIV)-_-A solution of $103 \mathrm{mg}$ of 8-episerratinine (XII) in $1.5 \mathrm{ml}$ of pyridine containing $1 \mathrm{ml}$ of acetic anhydride was heated at $100^{\circ}$ for $4 \mathrm{hr}$, cooled and evaporated to dryness in vacuo. The residue was taken up in water, made alkaline with $\mathrm{NH}_{4} \mathrm{OH}$ and extracted with $\mathrm{CHCl}_{3}$. The chloroform extract was dried over anhydr. $\mathrm{K}_{2} \mathrm{CO}_{3}$ and the solvent was evaporated. Recrystallization of the residue from acetone-ether gave $85 \mathrm{mg}$ of colorless pillars (XIV), $\mathrm{mp} 220.5-221^{\circ}$. Anal. Calcd. for $\mathrm{C}_{18} \mathrm{H}_{27} \mathrm{O}_{4} \mathrm{~N}: \mathrm{C}, 67.26$; $\mathrm{H}, 8.47$. Found: $\mathrm{C}, 66.83 ; \mathrm{H}, 8.70$. IR cm ${ }^{-1}: v_{0-\mathrm{H}} 3270 ; v_{\mathrm{C}=0} 1747,1732 ; v_{\mathrm{C}-0} 1236$. NMR $\tau: 5.17(1 \mathrm{H}$, clean q., $\left.J_{1}=5.5 \mathrm{cps}, J_{2}=11 \mathrm{cps},>\mathrm{CH}-\mathrm{OAc}\right) ; 6.48(1 \mathrm{H}, \mathrm{m} .,>\mathrm{CH}-\mathrm{OH}) ; 7.96(3 \mathrm{H}, \mathrm{s} .,-\mathrm{OCOCH}) ; 9.07(3 \mathrm{H}$, d., $\left.J=6 \mathrm{cps},>\mathrm{CH}-\mathrm{CH}_{3}\right)$.

8-Acetyl-13-dehydro-8-episerratinine (XV)__ To a cooled solution of $25 \mathrm{mg}$ of 8-acetyl-8-episerratinine (XIV) in $3 \mathrm{ml}$ of acetone was added $0.3 \mathrm{ml}$ of Jones' reagent with stirring and stirring was continued for further 30 minutes at $40^{\circ}$. After decomposition of excess reagent with $\mathrm{MeOH}$, the solution was evaporated to dryness in vacuo. The residue was dissolved in water, made alkaline with $\mathrm{NH}_{4} \mathrm{OH}$ and extracted with ether. The ethereal extract was dried over anhydr. $\mathrm{K}_{2} \mathrm{CO}_{3}$ and the solvent was evaporated. The residue was distilled at $165^{\circ}(2 \mathrm{~mm} \mathrm{Hg})$ to give an oily substance. Recrystallization of the distillate for $n$-hexaneether gave $8 \mathrm{mg}$ of colorless prisms $(\mathrm{XV}), \mathrm{mp} 169-170^{\circ}$. Anal. Calcd. for $\mathrm{C}_{18} \mathrm{H}_{25} \mathrm{O}_{4} \mathrm{~N}: \mathrm{C}, 67.69 ; \mathrm{H}, 7.89$. Found: C, $67.52 ; \mathrm{H}, 8.06$. IR $\mathrm{cm}^{-1}: v_{\mathrm{C}=0} 1740,1730,1705 ; v_{\mathrm{C}-0} 1235$. NMR $\tau: 4.79\left(1 \mathrm{H}, \mathrm{q} ., J_{1}=5.5 \mathrm{cps}\right.$, $\left.J_{2}=10.0 \mathrm{cps},>\mathrm{CH}-\mathrm{OAc}\right) ; 7.92\left(3 \mathrm{H}, \mathrm{s} .,-\mathrm{OCOCH}_{3}\right) ; 8.93\left(3 \mathrm{H}, \mathrm{d} ., J=6 \mathrm{cps},>\mathrm{CH}-\mathrm{CH}_{3}\right)$.

$\boldsymbol{\beta}$-Dihydroserratinine (XIX)—To a solution of $100 \mathrm{mg}$ of serratinine (I) in $20 \mathrm{ml}$ of $n$-propanol was added $100 \mathrm{mg}$ of metal sodium in small portions under reflux. After sodium had been completely dissolved, the reaction mixture was evaporated to dryness in vacuo, diluted with water and extracted with $\mathrm{CHCl}_{3}$. The extract was dried over anhydr. $\mathrm{K}_{2} \mathrm{CO}_{3}$ and the solvent was evaporated. Recrystallization of the residue from methanol-benzene gave $93 \mathrm{mg}$ of colorless prisms, (XIX), mp 210-211 . Anal. Calcd. for $\mathrm{C}_{16} \mathrm{H}_{27} \mathrm{O}_{3} \mathrm{~N}$ : $\mathrm{C}, 68.29 ; \mathrm{H}, 9.67$. Found: $\mathrm{C}, 68.11 ; \mathrm{H}, 9.80$. IR cm $\mathrm{IR}^{-1} ; v_{0-\mathrm{H}} 3410,3289 . \quad \beta$-Dihydroserratinine methiodide was prepared as usual in acetone and recrystallized from methanol to give colorless leaflets, $\mathrm{mp} 256-257^{\circ}$. Anal. Calcd. for $\mathrm{C}_{16} \mathrm{H}_{27} \mathrm{O}_{3} \mathrm{~N} \cdot \mathrm{CH}_{3} \mathrm{I}: \mathrm{C}, 48.23 ; \mathrm{H}, 7.14$. Found: C, 48.48; H, 7.13. IR $\mathrm{cm}^{-1}: \nu_{0-\mathrm{H}} 3360$. Oxidation of $\beta$-dihydroserratinine (XIX) with Jones' reagent gave bisdehydroserratinine* (XIII).

$\boldsymbol{\beta}$-Dihydroserratinine Methine $(\mathbf{X X})$ - A solution of $100 \mathrm{mg}$ of $\beta$-dihydroserratinine methiodide in $5 \mathrm{ml}$ of $\mathrm{MeOH}$ was stirred with freshly precipitated silver hydroxide at room temperature for 20 minutes, filtered and evaporated to dryness in vacuo. The residue was pyrolyzed at $160^{\circ}$ to give an oily distillate which was soluble in ether. Recrystallization of the distillate from ether gave $35 \mathrm{mg}$ of colorless prisms, $(\mathrm{XX}), \mathrm{mp} 174-175^{\circ}$. Occasionally, this material crystallized as colorless prisms which melted at 158$159^{\circ}$. These two different crystals were shown to be dimorphisms by cross seeding methods and comparison of their IR spectra in solution. Anal. Calcd. for $\mathrm{C}_{17} \mathrm{H}_{29} \mathrm{O}_{3} \mathrm{~N}: \mathrm{C}, 69.11 ; \mathrm{H}, 9.90$. Found: C, 69.37; H, 9.89. IR cm ${ }^{-1}: v_{\mathrm{O}-\mathrm{H}} 3401 ; v_{\mathrm{C}=0} 1709$ (Nujol); $v_{\mathrm{O}-\mathrm{H}} 3584,3472 ; v_{\mathrm{C}=\mathrm{O}} 1719\left(\mathrm{CHCl}_{3}\right) . \quad \mathrm{NMR} \tau: 6.14(2 \mathrm{H}, \mathrm{m} .,>\mathrm{CH}-\mathrm{OH})$; $7.73\left(3 \mathrm{H}\right.$, s., $\left.>\mathrm{N}-\mathrm{CH}_{3}\right) ; 9.02\left(3 \mathrm{H}, \mathrm{d} ., J=7 \mathrm{cps},>\mathrm{CH}-\mathrm{CH}_{3}\right)$.

Methiodide-Prepared as usual in acetone and obtained as colorless prisms, $\mathrm{mp} 285^{\circ}$, by recrystallization from $\mathrm{MeOH}$-acetone. Anal. Calcd. for $\mathrm{C}_{17} \mathrm{H}_{29} \mathrm{O}_{3} \mathrm{~N} \cdot \mathrm{CH}_{3} \mathrm{I}: \mathrm{C}, 49.43 ; \mathrm{H}, 7.38$. Found: C, 49.68; $\mathrm{H}, 7.33$.

Reduction of 8-Acetyl-13-dehydroserratinine (XXI) with $\mathbf{N a B H}_{4}$-A solution of $130 \mathrm{mg}$ of 8-acetyl13-dehydroserratinine (XXI) and $700 \mathrm{mg}$ of $\mathrm{NaBH}_{4}$ in $20 \mathrm{ml}$ of $\mathrm{MeOH}$ was heated for $3 \mathrm{hr}$ under reflux. After addition of $10 \mathrm{ml}$ of aq. $10 \% \mathrm{NaOH}$ solution, the mixture was heated for further $1 \mathrm{hr}$ and decomposition of the excess hydride was effected by addition of AcOH. The solution was then diluted with water, made alkaline with $\mathrm{NH}_{4} \mathrm{OH}$ and extracted with $\mathrm{CHCl}_{3}$. The chloroform extract was dried over anhydr. $\mathrm{K}_{2} \mathrm{CO}_{3}$. Removal of the solvent furnished crystals which upon thin-layer chromatography showed two spots. The mixture in $\mathrm{CHCl}_{3}$ was chromatographed on alumina and elution with $\mathrm{CHCl}_{3}$ gave $75 \mathrm{mg}$ of serratinine (I), mp $244-245^{\circ}$, which was identified with an authentic sample of serratinine by mixed melting point determination and infrared spectra comparison. Successive elution of chromatographic column with $\mathrm{MeOH}_{-} \mathrm{CHCl}_{3}$ (1:1) gave $15 \mathrm{mg}$ of colorless plates, $\mathrm{mp} 272-276^{\circ}$, which were identified with $\alpha$-dihydroserratinine** (XVIII) by comparison of infrared spectra and mixed melting point determination.

5-Deoxo-13-deoxyserratinine (XXII)__ A solution of $0.2 \mathrm{~g}$ of sodium in $10 \mathrm{ml}$ of triethyleneglycol was heated at $180^{\circ}$ and completely anhydrous hydrazine was distilled into this solution until it refluxed freely at $180^{\circ}$. To the cooled solution obtained above was added $100 \mathrm{mg}$ of 8-acetyl-13-dehydroserratinine* (XXI) and the mixture was refluxed at $180^{\circ}$ for $16 \mathrm{hr}$. Excess hydrazine was distilled off from the reaction 
mixture nutil the temperature of the solution had raised to $220^{\circ}$ and refluxing was continued for further $24 \mathrm{hr}$. The cooled solution was diluted with water and extracted with $\mathrm{CHCl}_{3}$. After drying over anhydr. $\mathrm{K}_{2} \mathrm{CO}_{3}$, the solvent was evaporated to left solid mass which was chromatographed over chloroform-alumina. Elution with $\mathrm{CHCl}_{3}$ gave $65 \mathrm{mg}$ of crystals which were recrystallized from $n$-hexane to afford colorless needles (XXII), $\operatorname{mp} 244-245^{\circ},[\alpha]_{\mathrm{D}}^{23}-31.6^{\circ}\left(c=0.57\right.$, EtOH). Anal. Calcd. for $\mathrm{C}_{16} \mathrm{H}_{25} \mathrm{ON}: \mathrm{C}, 77.06 ; \mathrm{H}, 10.91$. Found: C, $77.29 ; \mathrm{H}, 10.94$. IR $\mathrm{cm}^{-1}: \nu_{0-\mathrm{H}} 3155$.

8-Dehydro-5-deoxo-13-deoxyserratinine (XXII) - - A solution of $50 \mathrm{mg}$ of 5-deoxo-13-deoxyserratinine (XXII) in $2 \mathrm{ml}$ of aq. $90 \%$ AcOH was added dropwise to a stirred solution of $25 \mathrm{mg}$ of chromium trioxide in $0.7 \mathrm{ml}$ of aq. $90 \% \mathrm{AcOH}$ at room temeprature and the mixture was stirred at room temperature for $15 \mathrm{hr}$. After decomposition of excess reagent with $\mathrm{MeOH}$, the solution was evaporated to dryness in vacuo. The residue was taken up in water, made alkaline with $\mathrm{NH}_{4} \mathrm{OH}$ and extracted with $\mathrm{CHCl}_{3}$. The extract was dried over anhydr. $\mathrm{K}_{2} \mathrm{CO}_{3}$ and the solvent was evaporated. The residue in benzene was chromatographed on alumina. Elution with benzene gave colorless oil which was distilled at $90^{\circ}(0.014 \mathrm{~mm}$ $\mathrm{Hg})$ to afford $37 \mathrm{mg}$ of colorless plates (XXIII), $\operatorname{mp} 81-85^{\circ} ;[\alpha]_{\mathrm{D}}^{21}+71.9^{\circ}(c=1.64, \mathrm{EtOH}) ;[\phi]_{273}-1023^{\circ}$ (trough), $[\phi]_{308}+3735^{\circ}$ (peak) (RD in $\left.\mathrm{MeOH}\right)$. Anal. Calcd. for $\mathrm{C}_{16} \mathrm{H}_{25} \mathrm{ON}: \mathrm{C}, 77.68 ; \mathrm{H}, 10.19$. Found: C, 77.52; H, 10.13. IR $\mathrm{cm}^{-1}: v_{\mathrm{C}=0} 1704$.

8-Benzoyl-8-episerratinine (XXIV)—_To a solution of $150 \mathrm{mg}$ of 8-episerratinine (IX) in $6 \mathrm{ml}$ of pyridine was added $2 \mathrm{ml}$ of benzoyl chloride. The mixture was allowed to stand at room temperature overnight, poured into ice-water, made alkaline with $\mathrm{NH}_{4} \mathrm{OH}$ and extracted with ether. The ethereal extracts were shaken with aq. $5 \% \mathrm{HCl}$ solution and the acidic solution was then made alkaline with $\mathrm{NH}_{4} \mathrm{OH}$, and extracted with ether again. The ethereal extract was dried over anhydr. $\mathrm{K}_{2} \mathrm{CO}_{3}$ and the solvent was evaporated. The residue in benzene was chromatographed on alumina. Elution with benzene gave $100 \mathrm{mg}$ of crystals which were recrystallized from ether to give colorless pillars, (XXIV), mp $196-197^{\circ},[\alpha]_{\mathrm{D}}^{24}+55.3^{\circ}$ $\left(c=0.96, \mathrm{CHCl}_{3}\right) ;[\alpha]_{\mathrm{D}}^{32}+65.9^{\circ}(c=0.954$, EtOH $)$. Anal. Calcd. for $\mathrm{C}_{23} \mathrm{H}_{29} \mathrm{O}_{4} \mathrm{~N}: \mathrm{C}, 72.03 ; \mathrm{H}, 7.62$. Found: $\mathrm{C}, 71.87 ; \mathrm{H}, 7.89$. IR cm ${ }^{-1}: v_{0-\mathrm{H}} 3520,3150 ; v_{C=0} 1740,1694 ; v_{\text {aromatic }} 1600,1578$. NMR $\tau: 1.8-2(2 \mathrm{H}$, m., aromatic protons); $2.3-2.6\left(3 \mathrm{H}, \mathrm{m}\right.$., aromatic protons); $4.87\left(1 \mathrm{H}, \mathrm{q} ., J_{1}=12 \mathrm{cps}, J_{2}=6 \mathrm{cps},>\mathrm{CH}-\mathrm{OCO} \phi\right)$; $6.40(1 \mathrm{H}, \mathrm{m} .,>\mathrm{CH}-\mathrm{OH}) ; 8.98\left(3 \mathrm{H}\right.$, d., $\left.J=6 \mathrm{cps},>\mathrm{CH}-\mathrm{CH}_{3}\right)$.

Acknowledgement We are grateful to Miss Y. Mano, Kyoto University, for elementary ananlyses and to Dr. T. Shingu, Kyoto University, for NMR spectral measurements. 